\title{
Omphalolith: An Umbilical Concretion to Recognize
}

\author{
Kip Mihara, $M D^{1,2}$ \\ 'Emergency Department, San Francisco VA Medical Center, San Francisco, CA, USA; ${ }^{2}$ Department of Internal Medicine, University of California, \\ San Francisco, CA, USA.
} sweats. She did not know how long it had been present. On exam she had a painless, brownish-black, dryappearing mass (Fig. 1) protruding from her umbilicus. The mass was felt to be an Omphalolith or Umbilical Concretion. It was removed with gentle traction using forceps. It measured $3.5 \times 3.0 \times 1.0 \mathrm{~cm}$ with a brownishblack dry-appearing cap and an inferior aspect that was pearly-tan-white (Fig. 2). Histopathology showed a specimen composed of laminated keratin.

The word Omphalolith (Omphalith) is derived from the Greek words omphalos (navel) and lithos (stone). ${ }^{1}$ It refers to sebum and keratin that have accumulated into a stone-like concretion in an umbilical cleft. $^{2}$ Superficial

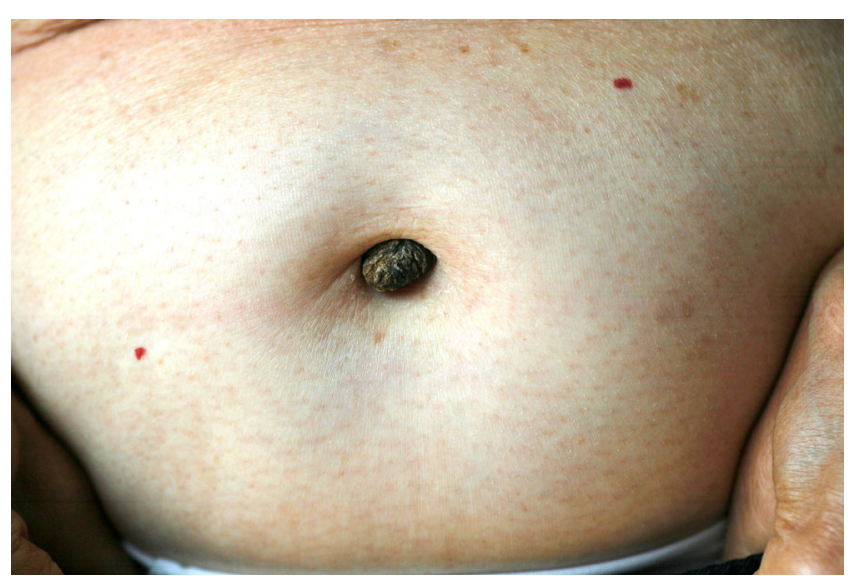

Figure 1. Omphalolith protruding from the umbilicus.

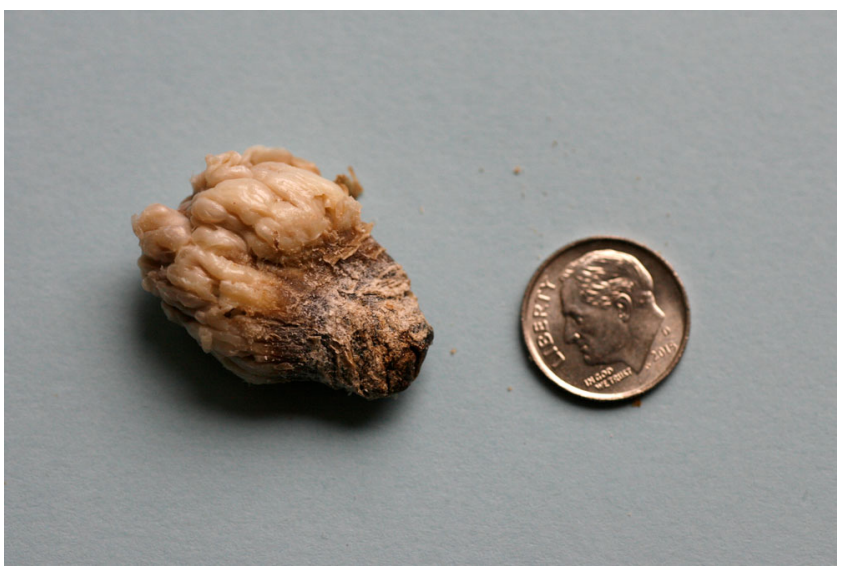

Figure 2. Omphalolith after removal, with a dark brownish-black superficial cap and pearly-tan-white base.

parts of the Omphalolith can appear dark brown or black, likely due to melanin and oxidation of lipids. ${ }^{3}$ It is usually asymptomatic, but can come to attention with skin ulcerations or secondary infections. ${ }^{1}$ Omphaloliths likely form when the patient fails to clean a deep umbilical cleft. They are removed with gentle manipulation. Recognition of the entity is important to prevent unnecessary consultations, procedures, and imaging studies.

Corresponding Author: Kip Mihara, MD; Emergency Department, San Francisco VA Medical Center, 4150 Clement Street, Mail code 111A3, San Francisco, CA 94121, USA (e-mail: kip.mihara@va.gov).

\section{Compliance with Ethical Standards:}

Funding: None.

Conflict of Interest: The author declares that he does not have a conflict of interest.

\section{REFERENCES}

Received March 4, 2016

Revised April 4, 2016

Accepted April 6, 2016

Published online April 25, 2016
1. Ichiki Y, Kitajima Y. Omphalith. Clin Exp Dermatol. 2008;34:420-421.

2. Gallouj S, Harmouch T, Amarti A, Fatima Z. Omphalolith: a rare entity but important to recognize. Dermatol Online J. 2014;20(5):14.

3. Sheehan D, Sarwat H, Vijayaraghavan G. Umbilical concretion. Radiol Case. 2011;5(4):25-31. 